\title{
Integrating Buprenorphine Treatment for Opioid Use with Primary Care is Associated with Greater Retention in Treatment
}

\author{
Anna G. Mirer, MD, PhD, MPH, Jeffrey D. Tiemstra, MD, Nicole E. Hammes, MD, \\ Heather M. Cloum, MD, MPH, and Karlee J. LaFavor, MD
}

Background: Medication-assisted treatment (MAT) for opioid use disorder (MAT) is encouraged for primary care use, but evidence for effectiveness when fully integrated with primary care versus provided separately is limited.

Method: We conducted a retrospective cohort study of 257 MAT patients in our family medicine clinic to assess retention in treatment for patients receiving MAT integrated with primary care compared with our MAT patients who received their primary care elsewhere.

Results: At 1 year after enrollment, 60\% of patients receiving MAT integrated with primary care remained in treatment versus $43 \%$ of patients who received their primary care separately. In multivariate analysis, the patients receiving integrated MAT had a significantly lower risk of dropout (hazard ratio 0.49, 95\% CI, 0.33-0.72).

Conclusion: In this rural family medicine clinic, MAT integrated with primary care was associated with higher retention in treatment. Providing MAT as a component of comprehensive primary care may be superior to referring patients to an outside source. (J Am Board Fam Med 2022;35:206-208.)

Keywords: Family Medicine, Medication-Assisted Treatment, Mental Health, Opioid-Related Disorders, Physicians, Primary Health Care, Retrospective Studies, Rural Health

\section{Introduction}

Medication-assisted treatment (MAT) for opioid use disorder (OUD) using buprenorphine (MAT) allows primary care physicians to effectively treat OUD in their own practices. ${ }^{1}$ Supporting data, however, are across a wide variety of settings, including specialized primary care clinics and sites where addiction medicine programs are colocated with primary care. ${ }^{2}$ The evidence supporting the effectiveness of MAT fully integrated into a primary care practice is very limited. $^{3}$ Effective integration of MAT into primary care may be an important goal for overall health, because it has been shown that patients receiving integrated MAT have higher participation in

This article was externally peer reviewed.

Submitted 13 July 2021; revised 31 August 2021; accepted 9 September 2021.

From Advocate Aurora Health Care, Milwaukee, WI (AGM, NEH); Advocate Aurora Health Care, Elkhorn, WI (JDT, HMC); Cuyuna Regional Medical Center, Crosby, $\mathrm{MN}(\mathrm{KJL})$.

Funding: none.

Conflict of interest: none.

Corresponding author: Jeffrey D. Tiemstra, MD, Advocate Aurora Health Care, Elkhorn, WI (E-mail: Jeffrey.tiemstra@ aah.org). preventive care than patients receiving MAT separate from their primary care. ${ }^{4}$

Our rural family medicine residency clinic began offering MAT in January 2018. Most of our MAT patients come by word of mouth, choose us as their primary care provider (PCP), and receive MAT integrated with their primary care, but because few other local physicians offer MAT, we also accept referrals from other physicians and see those patients only for MAT. This has created the opportunity to compare the effectiveness of receiving MAT integrated into primary care to receiving essentially the same MAT from a consultant separate from the patient's primary care practice. We assessed the effectiveness of integrated MAT versus separated MAT measured by retention in treatment.

\section{Methods}

We conducted a retrospective cohort study of all patients who received MAT in our clinic from January 2018 to January 2021. The study was deemed exempt from review by the Aurora Institutional Review Board. Electronic medical record data were abstracted for age; gender; psychiatric comorbidities; prior use of prescrip- 
Table 1. Predictors of Treatment Dropout in GenderAdjusted Multivariate Time to Event Analysis

\begin{tabular}{lcc}
\hline Variable & Hazard Ratio & $95 \% \mathrm{CI}$ \\
\hline $\begin{array}{l}\text { MAT integrated with primary care } \\
\text { Buprenorphine maintenance dose }\end{array}$ & 0.49 & $0.33-0.72$ \\
$\quad \geq 22 \mathrm{mg}$ daily & 0.53 & $0.30-0.95$ \\
$\quad 16$ to $20 \mathrm{mg}$ daily & 0.52 & $0.29-0.94$ \\
$\quad 10$ to $14 \mathrm{mg}$ daily & 0.95 & $0.51-1.79$ \\
$\begin{array}{l}\text { Participation in any behavioral } \\
\quad \text { health }\end{array}$ & 0.69 & $0.46-1.03$ \\
$\begin{array}{l}\text { Having an active diagnosis of } \\
\quad \text { depression }\end{array}$ & 0.63 & $0.42-0.93$ \\
$\begin{array}{l}\text { Having an active diagnosis of } \\
\quad \text { attention deficit disorder }\end{array}$ & 0.7 & $0.46-1.04$ \\
$\quad \begin{array}{l}\text { Unprescribed amphetamine/ } \\
\quad \text { methamphetamine use during }\end{array}$ & 1.69 & $1.13-2.53$ \\
$\quad \begin{array}{l}\text { MAT } \\
\text { Cocaine use during MAT }\end{array}$ & 1.39 & $0.93-2.07$ \\
$\begin{array}{l}\text { History of intravenous drug use } \\
\text { before MAT }\end{array}$ & 1.65 & $1.04-2.61$ \\
$\begin{array}{l}\text { History of heroin use before MAT } \\
\text { MAT }\end{array}$ & 1.11 & $0.65-1.89$ \\
\hline
\end{tabular}

MAT, Medication-assisted treatment; CI, confidence interval.

tion opioids, heroin, and IV drugs; date of first/last prescription; whether the patient had exited the program; buprenorphine maintenance dose; presence of opioids or other drugs of abuse on any urine sample; use of behavioral health services; and whether the patient identified us as their PCP. Data analysis was performed using Stata. Descriptive statistics and Kaplan-Meier curves were performed. Log-rank tests were used to select covariates for a multivariate Cox regression model of association with time to exiting the program accounting for right censoring. Probability of leaving the program within the first year of treatment was modeled using multivariate logistic regression models on the subset of subjects who entered the program 1 year or more before the end of the data collection period.

\section{Results}

The sample included 257 patients with a mean age of 38.3 years (range 22 to 77 ), $48 \%$ women. Of the $123(48 \%)$ patients receiving integrated MAT, 60\% remained in treatment at least 1 year versus $43 \%$ who received their primary care elsewhere. Table 1 shows the hazard ratios for variables associated with dropout rates using multivariate Cox regression analysis, and Figure 1 shows the Kaplan-Meier curve for integrated versus nonintegrated MAT.

\section{Discussion}

There are several potential explanations for the higher treatment retention with integrated MAT. Patient factors include a potentially higher level of motivation and readiness for success that includes the desire to improve overall health. Physician factors include possibly a more supportive therapeutic relationship when the physician is providing comprehensive whole-person care. Location factors include the convenience of receiving all care from 1 physician leading to better compliance with both MAT and primary care.

Limitations of the study include the retrospective design, although unlike a prospective controlled trial, this approach assesses the application of MAT in usual daily clinical practice. The sample size, while modest, was substantially larger than previous studies. ${ }^{2,3}$ Finally,

Figure 1. Survival in treatment for MAT patients with integrated primary care vs. separate primary care. Abbreviation: MAT, Medication-assisted treatment.

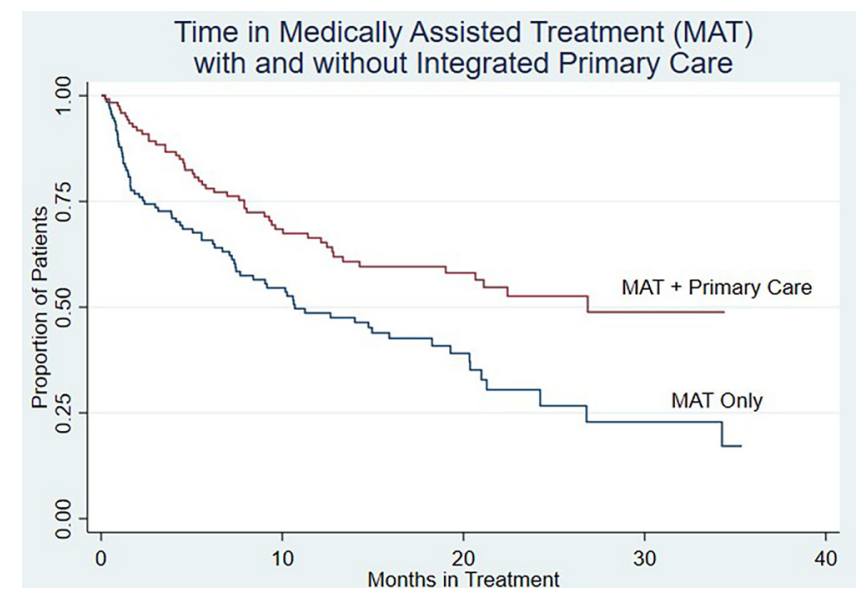


the study's single rural practice site does limit its generalizability. But in conclusion, family physicians should be aware that providing MAT to their own patients may in some settings be a better treatment option for OUD than referral to an outside source.

To see this article online, please go to: bttp://jabfm.org/content/ 35/1/206.full.

\section{References}

1. Lagisetty P, Klasa K, Bush C, Heisler M, Chopra V, Bohnert A. Primary care models for treating opioid use disorders: what actually works? A systematic review. PLoS One 2017;12:e0186315.
2. Roll D, Spottswood M, Huang H. Using shared medical appointments to increase access to buprenorphine treatment. J Am Board Fam Med 2015; 28:676-7.

3. Mintzer IL, Eisenberg M, Terra M, MacVane C, Himmelstein DU, Woolhandler S. Treating opioid addiction with buprenorphine-naloxone in community-based primary care settings. Ann Fam Med 2007;5:146-50.

4. Haddad MS, Zelenev A, Altice FL. Buprenorphine maintenance treatment retention improves nationally recommended preventive primary care screenings when integrated into urban federally qualified health centers. J Urban Health 2015;92:193-213. 